\title{
La formación en las universidades pedagógicas. Un punto de encuentro
}

TRAINING AT PEDAGOGICAL UNIVERSITIES. A MEETING POINT

a FORMAÇÃO NAS UNIVERSIDADES PEDAGÓGICAS. UM PONTO DE ENCONTRÓ

\author{
Alberto Martínez Boom* / almarboom@yahoo.com
}

\section{Resumen}

El siguiente artículo presenta un recorrido histórico alrededor de la formación de maestros en América Latina y la reforma educativa que actualmente se está implementando en México. Parte de las múltiples consideraciones políticas que han afectado de manera directa a las instituciones formadoras de maestros, ya que en las diferentes reflexiones que se gestan acerca de la calidad en la educación, se reconoce al maestro como la base de la misma. Es determinante, entonces, la participación de estos agentes transformadores en la construcción y legitimación de las políticas para lograr el éxito en la lucha por mejorar la educación.

\section{Abstract}

This article presents an overview on the history of teacher training in Latin America and on the educational reform currently being implemented in Mexico. It examines the many political considerations that have directly affected teacher training institutions, since in different reflections about the quality of education, teachers are recognized as the foundation of the same. Therefore, the participation of these transforming agents is crucial in the construction and legitimization of policies in order to achieve success in the struggle to improve education.

\section{Resumo}

O seguinte artigo apresenta um percorrido histórico sobre a formação de professores na América Latina e a reforma educativa que atualmente está sendo implementada no México. Esse baseia-se nas múltiplas considerações políticas que afetam diretamente as instituições de formação de professores, pois nas reflexões realizadas acerca da qualidade da educação, o professor é reconhecido como a base dela. É importante, então, a participação desses agentes transformadores na construção e legitimação das políticas para conseguir o sucesso na luta por melhorar a educação.
Palabras clave

Universidades pedagógicas, formación de maestros, experiencias

\section{Keywords}

pedagogic universities, teacher training, experiences

\section{Palavras chave}

Universidades pedagógicas, formação de professores, experiências

\footnotetext{
- Profesor titular de la Universidad Pedagógica Nacional. Miembro fundador del Grupo de Historia de la Práctica Pedagógica. Miembro de la Academia Colombiana de Pedagogía.
}

Fecha de recepción: 05 de octubre de 2015 / Fecha de aprobación: 30 de enero de 2016 
La formación ha dejado de ser la cuestión central de la universidad actual. Ni su concepto, ni su práctica, ni su experiencia, ni su historia parecen conmover, mucho menos convocar. Si la formación ya no es todo lo que era, nos queda la exigencia de problematizar las tensiones de una universidad reformada y modernizada.

Sus preocupaciones e intereses ahora son otros: aprendizaje, evaluación, gestión, acreditación, indicadores de calidad y todo aquello que denote productividad, emprendimiento, innovación y éxito. Por supuesto que la universidad puede entrar en la onda del mercado, pero cómo lo hace, a costa de qué, valorando qué, conservando qué, es la diferencia que permitirá afirmar lo que aún pueda quedar de la propia universidad.

En principio podríamos detenernos en dos cuestiones: primero, qué fuerzas explican las mutaciones de la formación, y segundo, qué del pensamiento sobre la formación se puede actualizar. Sabemos que cuando las prácticas formativas se mundializan, masifican, virtualizan y capitalizan, nociones como paideia, bildung, kultur y aufklärung se vuelven irreconocibles, en particular para universidades cuyas tradiciones carecen de arraigo, lo que impide problematizar la hondura de aquello que se anuncia como cambio.

Pensar este lugar compartido, pensar esta obsesión significa poder hacer convivir trabajos diferentes, biografías diferentes, disciplinas diferentes, generaciones diferentes, modos distintos de ver el mundo y la universidad, pero también la responsabilidad de tomar decisiones importantes sobre esa figura formativa: el maestro, que otros Ilaman profesor, docente, incluso función docente, y en cuya inestabilidad nos jugamos convicciones y pasiones profundas que vitalizan el trabajo de las universidades pedagógicas. En todo caso lo que aún es vigente es que la formación de maestros continúa siendo un punto de encuentro entre las universidades pedagógicas latinoamericanas.

\section{Lo que cambia: la formación}

En las últimas décadas la universidad ha perdido el monopolio que profesaba tanto sobre la formación como sobre la apropiación de las disciplinas. La for- mación, otrora un objeto de la pedagogía, hoy es otra cosa en manos de la tecnología y de la publicidad. Las ideas y prácticas en torno a la formación encontraron obstáculos difíciles, al tener que afrontar tanto la educación de masas como los procesos de modernización y virtualización educativa. La bien vista modernización de la universidad, acaballada en la idea de calidad educativa, descentró la formación de su viejo lugar, tal vez porque la formación es ese innombrable que no se deja ver como evidencia, que no es mostrable como indicador.

Tanto la mundialización de la economía como de las comunicaciones pusieron en marcha transformaciones que impactaron los sistemas de escolarización. Mundializar la educación significó convertirla en objetivo estratégico central no solo de los Estados sino de los mercados. Como se trata de sistemas en proceso de mutación, se necesitaron reformas para garantizar tanto la funcionalidad como la introducción de prescripciones universales capaces de optimizar el uso de nuevos medios formales y tecnológicos. Entre otras cosas, porque la masificación requiere de acciones diversificadas capaces de responder a las contingencias de las tecnologías sociales y materiales. Lo que explica todo un arsenal de planes y cambios que conforman una epidemia política de reformas a la universidad globalizada.

Un primer efecto pasa por el tiempo de la enseñanza que se valora, ahora, como lento y derrochador; en su defecto, nos lanzamos a la velocidad del aprendizaje. Edgar Faure en Aprender a ser la educación del futuro (1973) indica que "el acto de enseñar cede paso al acto de aprender", superando la concepción de una educación limitada en el tiempo y encerrada en el espacio. Semejante transformación en el énfasis de las actividades educativas hace emerger modelos mucho más flexibles, modelos que tendrán como característica la ampliación ad infinitum de una formación permanente y continua.

El tesoro del que habla el Informe Delors (1994) ya no consiste en la formación de un ciudadano útil sino de un sujeto capaz de hacerse cargo de sus propias necesidades y expectativas de aprendizaje en un mundo altamente competitivo. Aprender a competir pone en escena nuestra existencia en un mundo mucho más complejo. Esta variación introduce aumento de la eficacia, 
la eficiencia y la pertinencia; variaciones que se van a agrupar en un término genérico: calidad de la educación.

Semejante descentramiento exige del profesor un acto de abandono: privarse de su experiencia respecto de la enseñanza y por supuesto de la formación. Ya no sorprende que nuestra inteligencia haya convertido la aspiración a la formación en prácticas de aprendizaje, en gestión y competencias de profesionalización, en administración de un simulacro cuyo valor no se opone a las tradiciones formativas. La idea de la universidad como refugio para madurar el saber lejos de las preocupaciones de la vida cotidiana y donde se acude para beber en el recinto de la sabiduría, se ha vuelto anacrónica.

\section{Muta la formación, gana el aprendizaje}

Expresiones como coaching, aprendizaje apoyado en la web, teleaprendizaje, e-learning, aprendizaje electrónico, edu-entretenimiento, entre otras, describen una variación sustantiva del tiempo y del espacio en el que contemporáneamente se realiza la acción educativa. La antigua formación parece haber devenido en nuevos procedimientos, nombrados por los expertos como "modelos eficientes", dada su capacidad de resolver aspectos puntuales de las viejas rutinas, es decir, tecnologías de la velocidad, técnicas de la trasmisión y tecnologías de acción a distancia.

Una tecnología es mucho más que equipos y técnicas, se trata de un acoplamiento de relaciones sociales y humanas en el que los equipos y las técnicas son tan solo un elemento. Según Nikolas Rose (2012), una tecnología alude a un conjunto estructurado por una racionalidad práctica gobernada por un objetivo más o menos consciente; es decir, ensambles híbridos de conocimientos, instrumentos, personas, sistemas de juicio, edificios y espacios, sustentados por niveles programáticos.

Todo este modelamiento implica mínimamente lo siguiente:

- Modelos educativos de innovación: por medio de la tecnología es posible integrar enfoques constructivistas con aprendizaje social, en razón de sus atributos de interactividad que apuntan a la producción de comunidades de aprendizaje. Las nuevas tecnologías ejercen un poder de motivación fundamental para el proceso de aprendizaje de los individuos.

- Modelos de eficiencia y pertinencia: las nuevas tecnologías prometen construir conocimiento pertinente y actualizado, es decir, que los viejos contenidos e incluso los otrora currículos se pueden actualizar en términos de virtualización: contenidos virtuales de aprendizaje.

- Modelos de autoaprendizaje: las nuevas tecnologías permiten la personalización de los aprendizajes. En cada individuo existe una facultad creativa virtual susceptible de ser acumulada como competencia individual y vinculada con el trabajo inmaterial, hecho que acentúa el carácter cognoscitivo de las tareas.

- Modelos de inclusión y equidad: el acceso mediático es en sí mismo inclusivo. Miles de personas pueden tener acceso a un mismo contenido educativo. La cuestión pasa entonces por el diseño, la producción, la distribución y el uso de estos contenidos.

- Monitoreo y evaluación permanente de los modelos: tanto por sus usuarios como por sus gestores y participantes, las nuevas tecnologías parecen diversificar sus recursos educativos al tiempo que permiten el monitoreo, control y seguimiento permanente, ya no de los resultados sino de sus procesos, es decir, de la gestión.

\section{Repensar la formación en la universidad}

No se exagera si se advierte que ninguna de las propuestas formativas actuales parece disponerse a trabajar desde la experiencia del profesor. Es la falta de trabajo con la experiencia lo que explica tanto la pobreza de la formación como el malestar docente, la pérdida de autoridad en las aulas, el exceso de productivismo, la inconformidad y el sinsentido en las labores cotidianas de los maestros y de los formadores de maestros en las universidades pedagógicas.

Apostar por la experiencia encarna diversas dificultades. La experiencia no es un supuesto dado, nombrarla exige quebrar toda posible ingenuidad sobre la formación o sobre la identidad del maestro, para componer los trazos 
de unas experiencias en plural, presentes en discursos teóricos, institucionales y prácticos, susceptibles de configurar diagnósticos, trayectos y apuestas afirmativas sobre lo múltiple y lo diverso del devenir magisterial.

Eliminar la experiencia es el propósito central de varias propuestas de profesionalización docente actual. Un maestro sin experiencia se compromete rápidamente con el aprender a aprender, con el facilismo de las "pedagogías fashion" o de las "pedagogías light". Un maestro desprovisto de experiencia pierde valor, acepta sin crítica la educación centrada en el rendimiento, en las competencias, en la demencia de quien se asume como emprendedor de sí mismo. La eliminación de la formación pedagógica como requisito para el ejercicio docente no valoriza al maestro sino que lo funcionaliza, en particular, al cansancio de tener que devenir siempre una gestión exitosa de sí mismo.

Pensar la experiencia para repensar la formación pasaría por discutir mínimamente tres asuntos: primero, el valor de la experiencia; segundo, la articulación de la experiencia con la formación; y tercero, la experiencia como ejercicio de pensamiento.

\section{El valor de la experiencia}

La experiencia sirve para valorar, no puede ser productiva sino valorativa. "Dotar de valor" no es equiparable a una adquisición, no es algo que se transfiere. En este sentido, el valor pedagógico es intrínseco a la configuración de la experiencia del maestro porque le exige asumir posición frente a hechos y propuestas; le exige saber, construir respuestas y saberes propios.

Lo que interesa de la experiencia es el valor que agrega, su destello único y singular. La experiencia dota de valor porque contiene la ampliación tanto de lo que pensamos como de las posiciones que asumimos frente a los problemas. Si asumimos que la experiencia pedagógica del maestro se construye, que no la configura el simple paso por la institución, que no son los años de permanencia en un cargo o la acción rutinaria los que nos dota de experiencia, se hace necesario entonces direccionar los actos de formación hacia este valor de la experiencia pedagógica del maestro.
Ahora bien, configurar la experiencia, hacerla sonar y reivindicarla dista mucho de los lenguajes reduccionistas de quienes dicen hacer sistematización de experiencias. Descontaminar la palabra experiencia de estas simulaciones significa dejar de aplanarla en los lenguajes del "conocimiento alternativo" y de su espontaneísmo subalterno. Se trata de no hacer de la experiencia "una cosa, de no objetivarla, no cosificarla, no homogeneizarla, no calcularla, no hacerla previsible, no fabricarla, no pretender pensarla científicamente o producirla técnicamente" (Larrosa, 2003, p. 4). La experiencia vale porque su esfuerzo exige recuperar la voz del narrador, quebradiza voz que no coincide, afortunadamente, con el banal éxito publicitario.

\section{Experiencia y formación}

Una experiencia genuinamente formativa tendría el efecto de incitar la curiosidad, fortalecer la iniciativa y generar deseos intensos, genuinos, altivos. Nombrar la clásica relación de la experiencia con la formación significa reiterar cómo la experiencia es

[...] lo que me pasa y lo que, al pasarme, me forma o me transforma, me constituye, me hace como soy, marca mi manera de ser, configura mi persona y mi personalidad. Por eso el sujeto de la formación no es el sujeto de la educación o del aprendizaje sino el sujeto de la experiencia: es la experiencia la que forma, la que nos hace como somos, la que transforma lo que somos y lo convierte en otra cosa. (Larrosa, 2003, p. 7).

En esto se encuentran pedagogía y formación, en la puesta en juego de una serie de conceptos para orientar la práctica pedagógica y valorar sus efectos, de forma que se vaya reformulando y reconstruyendo permanentemente. Es por la insistencia en la experiencia que podemos problematizar la autoridad pedagógica del maestro y su relación asimétrica con los estudiantes. Si la experiencia deviene en formación subjetiva, es también una fuente de producción de saber.

La formación como experiencia de las universidades pedagógicas señala que nuestros asuntos no se resuelven con un didactismo pragmático y facilitador. Cuando la formación apuesta por construir la experien- 
cia del maestro, cualquiera que sea el umbral en que aquella se desarrolle, se convierte en una disposición ética y cultural que ayuda al maestro a movilizar su pensamiento, a pensarse de otras maneras y a asumir su quehacer como sujeto potente. Esta posición lo distancia de su rol como simple funcionario.

\section{Experiencia y pensamiento}

La formación orientada a construir la experiencia del maestro produce "afectación". La experiencia se conecta y se realiza en sintonía con el acto de pensar. El pensamiento es el articulador entre experiencia y pedagogía, es a partir de actos de pensamiento que el maestro pregunta, discute, se interroga, arriesga, problematiza y configura su experiencia. Como dice Dewey: “Ninguna experiencia con sentido es posible sin algún elemento del pensamiento" (1995, p. 128); pensar traduciría un "esfuerzo intencional para descubrir las conexiones especificas entre algo que nosotros hacemos y las consecuencias que resultan, de modo que ambas cosas lleguen a ser continuas" (1995, p. 129).

La experiencia articula razón y acción, espíritu y cuerpo. Está atravesada por los sentidos y el pensamiento, pero no es solo experimentar en tanto ensayo y error, se trata de experienciar: sentir, vivir, sufrir, reflexionar los hechos, repensarlos hasta convertirlos en experiencia vital. Estas precisiones permiten afirmar que las experiencias pedagógicas son singulares, distinción que establece distancias con las Ilamadas "innovaciones educativas" o "experiencias significativas" que buscan replicarse masivamente en cualquier lugar y con otros actores.

La educación exige de nosotros algo del orden de la inauguración de la novedad. Inaugurar novedad no implica renunciar a lo antiguo ni desconocer la historia. Simplemente habilitarnos a pensar que quizá haya otros modos posibles, llevamos mucho tiempo de historia pensado que hay un solo camino, una única respuesta. (Frigerio, 2004, p. 5).

Pensar como un ejercicio vital, en movimiento para descolocarnos, es algo que siempre es posible sobre todo en instituciones como la universidad. La existencia de la universidad se justifica al ser capaz de sostener, insistir y mantener un compromiso activo (afirmativo) con la formación, es decir, con su propia experiencia de formación. En esto radica su vitalidad, olvidarlo supone aniquilar la universidad o por lo menos borrar su rostro al oscurecerla, enrarecerla, deslegitimarla.

Los lenguajes actuales, rutinarios y atrapantes de los desafíos, las competencias, la acreditación, la innovación, expresan una misma desesperación: operan bajo una lógica que reduce, simplifica, homogeniza y desarraiga el trabajo con la formación. Así, el lenguaje de la innovación aminora la creatividad, tanto como los simulacros repetitivos de la acreditación aíslan y dividen la tarea de formación.

No imagino una violencia mayor para la propia universidad. No hay exageración en esta forma de violencia, tan técnicamente diseñada, sus efectos son claros: destruye la universidad como comunidad, aísla su lenguaje, imposibilita toda cercanía, oscurece sus tradiciones y erosiona su compromiso ético con la construcción de lo público.

\section{Referencias}

Delor's, J. et al. (1996). La educación encierra un tesoro. Madrid: Santillana.

Dewey, J. (1995). Democracia y educación. Madrid: Morata.

Faure, E. et al. (1973). Aprender a ser. Madrid: Alianza Editorial, Unesco.

Frigerio, G. (2004). Formación y experiencia en la universidad. Revista Colombiana de Educación, 70, 305-317.

Larrosa, J. (2003). La experiencia y sus lenguajes. [Conferencia]. Barcelona: Universidad de Barcelona.

Rose, N. (2012). Políticas de la vida. Biomedicina, poder y subjetividad en el siglo XXI. Buenos Aires: Universidad de la Plata. 


\section{Diálogo de conocimiento}

El artículo nos convoca a mirar un asunto que comúnmente no es abordado en los debates sobre la formación de los maestros, y es el cambio profundo, cultural que se está dando en relación con la escuela, la pedagogía y la enseñanza. Es un un llamado de atención sobre el impacto que tiene para la formación de maestros el hecho de que ahora toda la acción pedagógica gira alrededor del aprendizaje, la gestión y la evaluación. Se trata de un cambio histórico de larga duración que tal vez no hemos dimensionado de manera suficiente.

Es un artículo de lectura urgente, pues sin comprender estos asuntos seguiremos divagando sobre cuestiones de forma y no de fondo en el debate, no solo sobre las licenciaturas y las Escuelas Normales, sino sobre lo que significa ser maestro hoy, y más aun, sobre la vigencia histórica de la escuela como escenario para la formación de niños y jóvenes. Las otras alternativas de educación permanente centradas en el aprendizaje nos llevarán por el abismo de la incertidumbre, y tal vez sea tarde.

Alejandro Álvarez Gallego 